\title{
"Pseudosarcoma" in a pregnant woman
}

\section{Amarjit Anand*, Eva Maria Tsapakis, Ali A Narvani, Ali Alhakim, Steve R Cannon and Eleftherios Tsiridis}

\author{
Address: Royal Free and University College London Hospitals, Royal National Orthopaedic Hospital, Bone Tumour Unit, Brockley Hill, Stanmore, \\ Middlesex, HA7 4L, UK \\ Email: Amarjit Anand* - amarjitanand@doctors.org.uk; Eva Maria Tsapakis - emtsapakis@doctors.org.uk; \\ Ali A Narvani - alinarvani@hotmail.com; Ali Alhakim - alhaksi@yahoo.com; Steve R Cannon - elise.cannon@tesco.net; \\ Eleftherios Tsiridis - etsiridis@hotmail.com \\ * Corresponding author
}

Published: 18 January 2007

World Journal of Surgical Oncology 2007, 5:7 doi:10.1 I86/I477-78/9-5-7

This article is available from: http://www.wjso.com/content/5/I/7

(c) 2007 Anand et al; licensee BioMed Central Ltd.

This is an Open Access article distributed under the terms of the Creative Commons Attribution License (http://creativecommons.org/licenses/by/2.0), which permits unrestricted use, distribution, and reproduction in any medium, provided the original work is properly cited.

\begin{abstract}
Background: Intravascular fasciitis (IVF) is a rare benign condition characterised by reactive myofibroblastic proliferation arising from the superficial or deep fascia and involving arteries and/ or veins. It is a distinct variant of the more common condition of nodular fasciitis, which possesses similar clinical and histological features to IVF, but lacks vascular invasion. A thorough review of the literature revealed 26 reported cases of IVF.

Case presentation: We report a case of IVF in a 16-week pregnant lady affecting the hypothenar eminence of the hand associated with the ulnar artery.

Conclusion: The characteristic involvement of muscular arteries and veins by reactive myofibroblastic proliferation in IVF suggests a malignant component and often leads to an inappropriate diagnosis for this benign condition. We propose that hormone-related changes associated with pregnancy may play an important role in the aetiopathogenesis of this myofibroblastic lesion.
\end{abstract}

\section{Background}

Intravascular fasciitis (IVF) is a term originally described by Patchefsky and Enzinger to describe this distinctive variant of nodular fasciitis [1]. It is a benign, reactive myofibroblastic proliferative lesion that arises from the superficial or deep fascia and involves predominately small to medium-size arteries and/or veins. It presents as a well-defined nodule in the subcutis or muscle. The involvement of muscular vessels can lead to an erroneous assumption of malignant vascular invasion. It is considered to be very rare and since its first description in 1981, only a few isolated cases have been documented in the literature [2-8].

\section{Case Presentation}

In August 2003, a 20-year-old 16-week pregnant mother of one, presented to the orthopaedic outpatient clinic with a 2-month history of a slowly growing painless mass located in the right hypothenar eminence. She was righthand dominant and a housewife. There was no history of trauma, insect bites or drainage from the area. There was no significant past medical or surgical history. She was not on any prescribed medication. There was no family history of tumours. She denied smoking, alcohol and drug abuse. On examination, a non-tender, firm to palpation, well-demarcated and tethered to the subcutaneous tissues mass, surrounded by mild erythema, and measuring 
approximately $2.5 \mathrm{~cm} \times 3.0 \mathrm{~cm}$ was revealed, in the absence of palpable lymph nodes at the ipsilateral elbow or axilla. There were no other abnormal signs.

Haematological and biochemical investigations were within the normal range. A plain X-ray of the right hand and forearm was unremarkable. Magnetic resonance imaging showed the mass to have infiltrated all skin layers and to have encircled the ulnar artery without involvement of the underlying bones (Figure 1). The absence of a signal void from within the mass excluded a diagnosis of haemangioma. Ultrasound-guided needle biopsy showed lesional areas consistent with collagenous fibrous tissue of varying cellularity, with little evidence of mitotic activity. Immunohistochemistry showed focal positivity for smooth muscle actin (SMA), suggesting myofibroblastic differentiation. Histological appearances were in keeping with fibromatosis.

Three weeks after initial presentation, the lesion was excised preserving the ulnar nerve and artery. Histology showed a multi-nodular, well-circumscribed uniform spindle cell lesion with varying cellularity and fibrosis. In one section, central cyst formation was observed. Occasional mitoses of normal morphology were seen. Necrosis was not a feature. In several areas, the lesion appeared to be intravascular, the vessel was lined by an apparent endothelium (Figure 2). Scattered osteoclast-like multinucleate giant cells were also observed. Immunohistochemistry replicated diffuse positivity for SMA, but not for desmin, CD34 or S100 protein. Appearances were consistent with a myofibroblastic proliferation, confirming a diagnosis of intravascular fasciitis (IVF).

The patient had an uneventful recovery and required no further therapy. She continues to be evaluated for local recurrence every 6 months, with no sign of recurrence at the 2-year follow-up.

\section{Discussion}

IVF was first described as a subset of cases closely resembling the clinical and histological picture of nodular fasciitis (NF) [1]. Recognition of IVF as a variant of NF rather than as a vascular neoplasm, or as a low-grade sarcoma, which demonstrates local infiltration of normal tissue and intravascular involvement, is necessary to avoid over-diagnosis and over-treatment of this benign myofibroblastic lesion. IVF originates from fibroblasts associated with arterial or venous walls, and is thought to represent reactive overgrowth of normal cells without malignant transformation. Histologically, IVF is characterised by fibroblasts arranged in fascicles and bundles, with oval, pale-stained nuclei and occasional prominent nucleoli. Typical mitotic figures may be present. The intracellular matrix is rich in mucopolysaccharides, with extravasated erythrocytes, foamy macrophages, and occasional multinucleated giant cells present $[8,9]$.

Pre-existing trauma, viral infection, and venous thrombosis resulting in myofibroblastic transformation of the vessel wall have all been implicated in the aetiopathogenesis of IVF, but there was no evidence for either of these in our case affecting the hypothenar eminence. Pregnancy was the only significant co-existing medical condition.

We hypothesised that hormone-related changes seen during pregnancy may have contributed to the development of IVF in our patient. Oestrogen in particular, has for long been known to stimulate fibroblast and smooth muscle cell types and has been implicated in fibroproliferative diseases such as carpal tunnel syndrome, Dupuytren's contracture, and dermoid tumours. A weak presence of oestrogen receptors has also previously been demonstrated in nodular fasciitis [10]. Oestrogen-related proliferation of fibroblasts and smooth muscle cells is very rapid in early pregnancy due to higher oestrogen levels and decreases progressively thereafter [11].

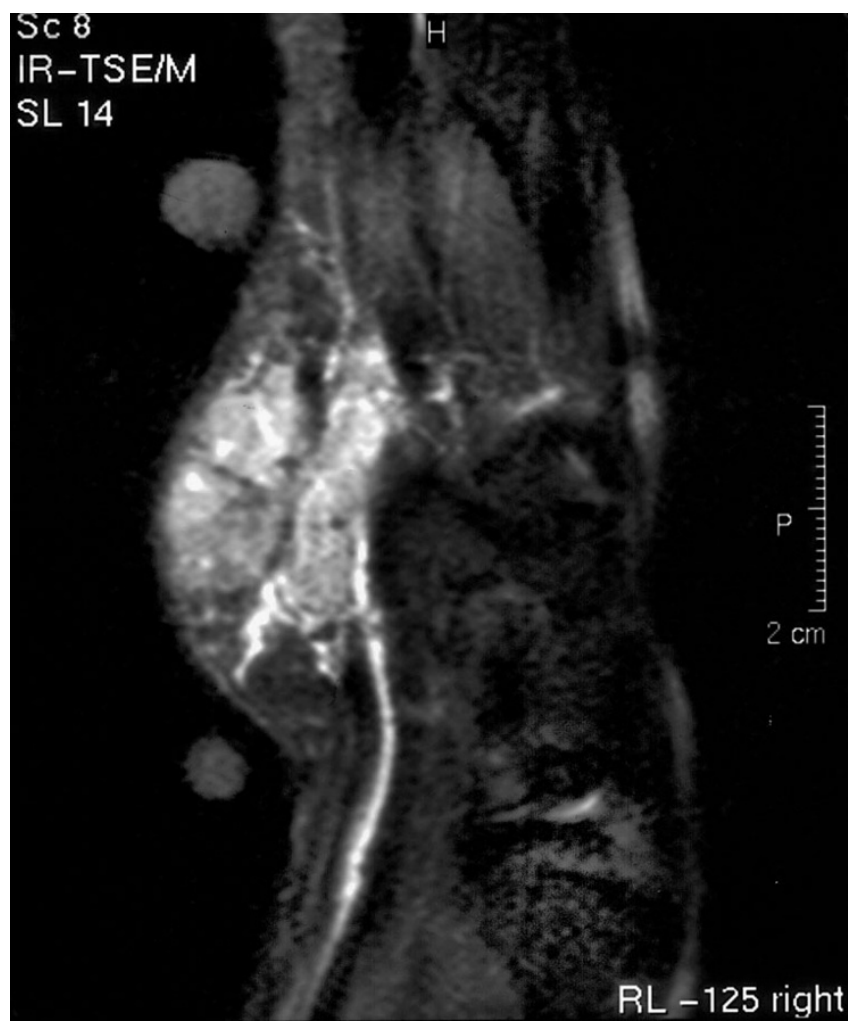

Figure I

MRI of the right hand showing a pseudosarcomatous mass encircling the ulnar artery. 


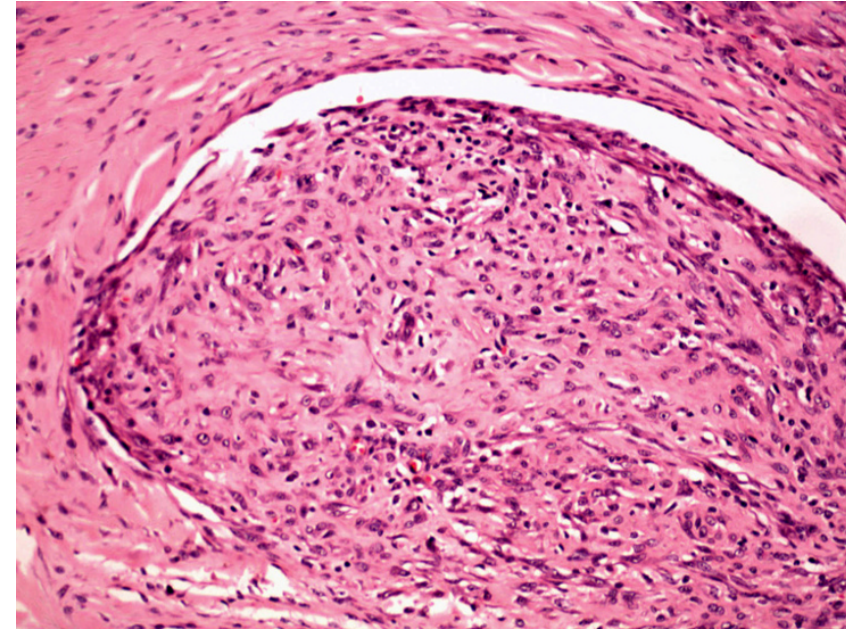

Figure 2

Section demonstrating an intravascular proliferation of uniform spindle cells. (H\&E $\times 10)$.

\section{Conclusion}

IVF is a benign myofibroblastic proliferative lesion that involves arteries and/or veins, a feature distinguishing it from other pseudosarcomatous proliferative lesions. Nevertheless, it may be easily mistaken for a malignant sarcomatous invasion of the vasculature. Based on our case presentation, we propose that pregnancy and oestrogenrelated changes may be another risk factor for IVF and play an important role in the aetiopathogenesis by influencing proliferative changes in fascia myofibroblasts, however, more research and further cases need to be studied prior to establishing such hypothesis.

\section{Competing interests}

The author(s) declare that they have no competing interests.

\section{Authors' contributions}

$\mathrm{AA}^{1}$ reviewed the literature and prepared the manuscript. $\mathrm{SRC}^{5}$ provided the case and revised the manuscript. $\mathrm{AN}^{3}$ obtained patient consent and helped in preparation of the manuscript. $\mathrm{ET}^{6}$ and $\mathrm{EMT}^{2}$ conception and identification of case hypothesis, critical revision of the manuscript and coordination of the study. $\mathrm{AA}^{4}$ provided the histology images and histology information. All authors read and approved the final manuscript.

\section{Acknowledgements}

Written consent was obtained from the patient for publication of this case report.

\section{References}

I. Patchefsky AS, Enzinger FM: Intravascular fasciitis: A report of 17 cases. The American Journal of Surgical Pathology I98I, 5(I):29-36.

2. Beer K, Katz S, Medenica M: Intravascular Fasciitis: Correspondence. International Journal of Dermatology 1996, 35(2): |47-|48.
3. Freedman PD, Lumerman H: Intravascular Fasciitis: Report of two cases and review of the literature. Oral Surgery 1986, 62(5):549-554.

4. Ito M, Matsunaga K, Sano K, Sakaguchi N, Hotchi M: Intravascular fasciitis of the forearm vein: $A$ case report with immunohistochemical characterisation. Pathology International 1999, 49: I75-179.

5. Kahn MA, Weathers DR, Johnson DM: Intravascular fasciitis: A case report of an intraoral location. J Oral Pathology 1987, 16:303-306.

6. Price SK, Kahn LB, Saxe N: Dermal and Intravascular Fasciitis: Unusual Variants of Nodular Fasciitis. The American Journal of Dermatopathology 1993, I 5(6):539-543.

7. Samaratunga H, Searle J, O'Loughlin B: Intravascular Fasciitis: A case report and review of the literature. Pathology 1996 28:8- I I

8. Sticha RS, Deacon JS, Wertheimer SJ, Danforth RD: Intravascular Fasciitis in the Foot. The Journal of Foot and Ankle Surgery 1997, 36(2):95-99.

9. Enzinger FM, Weiss SW: Benign fibrous tissue tumours. In Soft Tissue Tumors 3rd edition. Edited by: Enzinger FM, Weiss SW. Mosby Year Book, St Louis; 1995: I65-200.

10. Kayaselcuk F, Demirhan B, Kayaselcuk U, Ozerdem OR, Tuncer I: Vimentin, smooth muscle actin, desmin, S- 100 protein, $\mathrm{p53}$, and estrogen receptor expression in elastofibroma and nodular fasciitis. Ann Diagn Pathol 2002, 6(2):94-9.

II. De Cian F, Delay E, Rudigoz RC, Ranchere D, Rivoire M: Desmoid tumour arising in caesarean section scar during pregnancy: monitoring and management. Gynecologic Oncology 1999. 75: $145-148$.
Publish with Biomed Central and every scientist can read your work free of charge

"BioMed Central will be the most significant development for disseminating the results of biomedical research in our lifetime. " Sir Paul Nurse, Cancer Research UK

Your research papers will be:

- available free of charge to the entire biomedical community

- peer reviewed and published immediately upon acceptance

- cited in PubMed and archived on PubMed Central

- yours - you keep the copyright
BioMedcentral 